\title{
ETNOECOLOGIA DO CAMBUCI (CAMPOMANESIA PHAEA (O. BERG) LANDRUM) PELA POPULAÇÃO DE PARANAPIACABA, SUDESTE DO BRASIL
}

\author{
Cristiane Campanini* \\ Ana Paula do Nascimento Lamano-Ferreira** \\ Maria Solange Francos*** \\ Mauricio Lamano-Ferreira****
}

RESUMO: A relação do homem com a natureza é tão antiga quanto a sua própria história. No entanto a biodiversidade tem sido ameaçada pelas atividades humanas. Assim, o presente trabalho se propôs a conhecer a relação de uma população humana urbana com uma espécie arbórea, conhecida como cambuci (Campomanesia phaea (O. Berg) Landrum), bastante utilizada para diferentes fins e de relevante interesse ecológico, próximo a uma área de conservação na Mata Atlântica, Sudeste do Brasil. Para isso, foi analisada a população da vila de Paranapiacaba, cidade de Santo André, SP, a qual mantém relação estreita com o cambuci. Foram realizadas 50 entrevistas com moradores e comerciantes locais que concordaram em participar, utilizando-se do método bola de neve e de conversas informais. Foram levantados na entrevista os diversos usos e aplicações do fruto de cambuci, bem como outros aspectos relacionados à ecologia da planta. Os entrevistados demonstraram conhecimento sobre os visitantes florais da $C$. phea e prováveis dispersores de seus frutos. Em relação ao plantio de mudas, os dados indicam que a comunidade humana promove o plantio da espécie uma vez que a utiliza como recurso para diversos fins e produz mudas por meio de sementes e brotos retirados da mata. Um dos principais usos do cambuci pelos moradores de Paranapiacaba foi o de alimento, sendo o fruto encontrado em diversas formas como como geleias, licores, cachaça, mousse, sorvete, bolo, além do tradicional suco na região.

PALAVRAS-CHAVE: Conservação da biodiversidade; Alimentação; Etnobotânica, Sustentabilidade.

Bióloga pela Universidade Nove de Julho (UNINOVE), Brasil.

** Bióloga, Doutora em Ecologia Aplicada (ESALQ/USP). Docente do Mestrado Profissional em Gestão Ambiental e Sustentabilidade-GEAS/UNINOVE, Brasil. E-mail: apbnasci@yahoo.com.br

*** Bióloga e Docente do Departamento de Saúde II da Universidade Nove de Julho (UNINOVE), Brasil.

${ }^{* * * *}$ Docente do Mestrado em Cidades Inteligentes e Sustentáveis-CIS da Universidade Nove de Julho (UNINOVE), Brasil. 


\section{ETHNO-ECOLOGY OF THE CAMBUCI (Campomanesia phaea (O. Berg) LANDRUM) BY THE PEOPLE OF PARANAPIACABA, SOUTHEASTERN BRAZIL}

ABSTRACT: Human and nature relationships are as old as history. However, biodiversity is in danger through anthropic activities. Current analysis studies the relationship between urban populations and the tree species Campomanesia phaea (O. Berg) Landrum, popularly known in Brazil as cambuci, greatly used for different ends, close to a conservation area in the Atlantic Rainforest in southeastern Brazil. The population of the district Paranapiacaba, in Santo André SP Brazil, closely related to cambuci, was analyzed. Fifty interviews with local residents and shopkeepers were undertaken through informal conversation and speech association. The different plant usages were discussed, coupled to other aspects of the plant's ecology. The interviewed manifested knowledge on the floral visitors of $C$. phea and the fruit's probable spreaders. Data on plantlets indicate that people enhance the species due to their usage for different aims and produce plantlets by seeds and buds retrieved from the woods. The main use of the cambuci by residents in Paranapiacaba is food made from its fruits, such as jelly, liquor, alcoholic beverage, mousse, ice cream, cake, and the region's traditional juice.

KEY WORDS: Conservation of biodiversity; Feeding; Ethno-botany; Sustainability.

\section{INTRODUÇÃO}

A espécie humana sempre se relacionou com os elementos da natureza de forma que pudesse manter suas populações viáveis e estáveis ao longo do tempo. Porém, desde a Revolução Industrial, esse modo de vida tem deixado alguns impactos negativos, principalmente no âmbito da conservação da biodiversidade. $\mathrm{O}$ uso inadequado de alguns recursos naturais, principalmente daqueles que se encontram na base das cadeias alimentares, pode ser bastante perigoso e alterar parte da comunidade de determinada área (SARMENTO et al., 2013). Assim, a conservação da biodiversidade tem-se tornado cada dia mais importante, principalmente nos aspectos que tangem à relação da população humana com outras espécies (TOLEDO, 2001).

Atualmente, há necessidade de conservação dos recursos naturais em biomas 
que têm sofrido a ação antrópica há muitos séculos, como é o caso da Mata Atlântica (CINCOTTA et al., 2000). Entretanto, mesmo em forte pressão da vida moderna, em algumas regiões urbanizadas prevalecem hábitos e costumes adquiridos ao longo do tempo (MONTELES; PINHEIRO, 2007). Esses conhecimentos tradicionais, resultado de relação mais estreita com a natureza, trazem contribuições para a compreensão dos ecossistemas como também para a administração e proteção dessas áreas (PEREIRA; DIEGUES, 2010).

A relação que determinada população tem com as plantas e suas interações com outros grupos de seres vivos, bem como seus saberes sobre esses organismos no meio ambiente são estudados pela etnobotânica e etnoecologia. Essas ciências são relativamente novas e se iniciaram a partir dos estudos sobre populações tradicionais e os recursos vegetais a partir da segunda metade do século passado (OLIVEIRA et al., 2009; PEREIRA; DIEGUES, 2010). Com base nesses estudos, pesquisadores iniciaram a busca por vínculos entre conservação e manejo de recursos naturais, o que tem tornado fundamental a investigação da percepção de populações urbanizadas em relação ao meio ambiente que o envolve (DORIGO; LAMANO-FERREIRA, 2015).

Ainda que os temas das pesquisas brasileiras no campo da etnobotânica e etnoecologia sejam muito amplos e distintos, abrangendo desde estudos de caráter filosóficos até aqueles voltados para a aplicação nas áreas industrial, médica, entre outras (OLIVEIRA et al., 2009), o conhecimento popular a respeito do uso e cultivo de plantas está intrinsecamente associado à manutenção e permanência de determinada espécie no meio (FARIA, 2002).

De acordo com Oliveira (2010), a imprescindível participação do conhecimento popular na conservação da biodiversidade e a colaboração da etnociência, por meio de seus trabalhos, fornecem importante material para a conservação das riquezas naturais e das populações que fazem uso destas, pois aproximam o conhecimento popular do conhecimento científico, tornando-se importante ferramenta de conservação de cada área em particular. Dessa forma, a etnoecologia amplia o trabalho acadêmico para sua prática em benefício de todos (MING, 2001), assegurando, assim, que o conhecimento secular a respeito do uso de espécies vegetais e suas interações não se percam no tempo (PIRES et al., 2009).

Diferentes áreas podem abordar e utilizar informações sobre 0 conhecimento de uma população sobre os recursos vegetais ou sobre o uso de uma 
planta específica. O estudo da relação de uma população com as plantas implica em maiores conhecimentos sobre o próprio vegetal, o homem e sua cultura (VIGANÓ et al., 2007), inclusive ao que se refere ao uso de vegetais na alimentação (SIVIEIRO et al., 2011; LAMANO-FERREIRA et al., 2016), que integra a preservação dos recursos e a transmissão cultural (BALDAUF et al., 2009).

Alguns trabalhos têm destacado a importante relação do homem com as plantas, como é o caso de Souza (2011), o qual estudou o enriquecimento florestal com espécies frutíferas como o cambuci. $\mathrm{O}$ autor ressaltou as implicações socioambientais pelo grande potencial econômico e alternativa para sistemas agrícolas tradicionais. A autora ainda finalizou seu estudo, relatando a falta de informações sobre o crescimento e sobrevivência da espécie na literatura científica. Assim, o presente trabalho é resultado da investigação do cultivo e usos do fruto de cambuci, pela população da vila de Paranapiacaba, localizada na cidade de Santo André, São Paulo.

\section{METODOLOGIA}

\subsection{LOCAL DE ESTUDO}

A vila de Paranapiacaba está localizada a $60 \mathrm{~km}$ do marco zero da cidade de São Paulo e a sudeste da cidade de Santo André, SP. A região se encontra entre o planalto Paulista e a serra do Mar (Figura 1), sendo este um dos maiores contínuos de mata preservada do bioma Mata Atlântica. Possui cerca de 55\% de seu território em áreas de mananciais e uma população atual de cerca de 1.100 habitantes (PPSA, 2014).

Em uma visão panorâmica, percebe-se que a vila de Paranapiacaba está sobre um grande vale, subdividindo-se entre a parte baixa (antiga Vila Velha) e a parte alta, que abriga o Largo da Igreja. Os índios tupis, ao usarem a região como rota para o planalto Paulista, denominaram-na de Paranapiacaba, significando "de onde se vê o mar", e foi a partir dessa rota, em 1867, que se deu início à construção da via ferroviária Santos-Jundiaí pela empresa inglesa São Paulo Railway Company, 
inserindo a participação ativa da vila no processo de industrialização da região metropolitana de São Paulo.

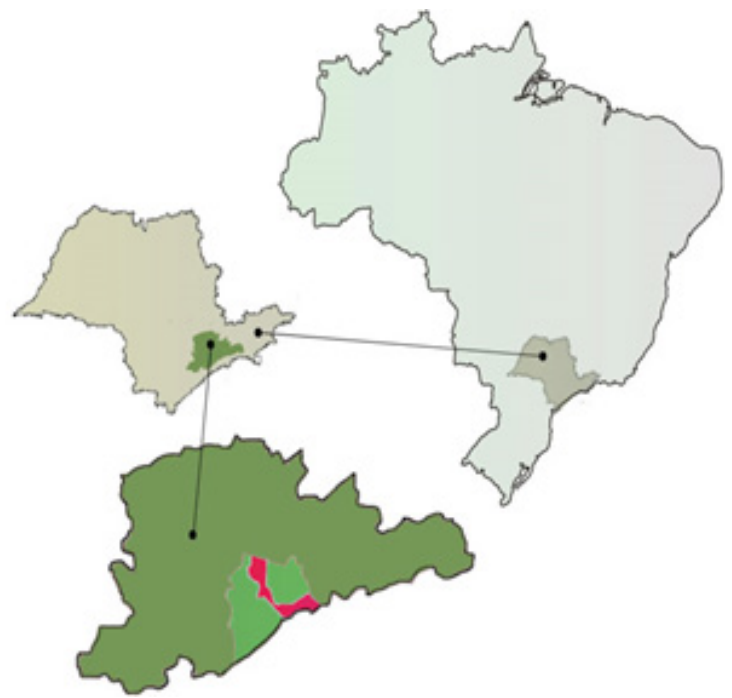

Figura 1. Mapa do município de Santo André, com destaque para a vila de Paranapiacaba.

Fonte: EcoDreams Estudo do Meio e Turismo Ecológico. Disponível em: http://www.ecodreams. com.br/como_chegar_br_sp_paranapiacaba.html

\subsection{CARACTERÍSTICAS DA Campomanesia phaea (O. Berg) Landrum}

Campomanesia phaea (O. Berg) landrum é uma árvore típica da Mata Atlântica, com altura de 3 a 5m, ocorrendo desde a serra do Mar de São Paulo até Minas Gerais (LORENZI, 1992). No passado, sua ocorrência era tão grande na cidade de São Paulo que chegou a dar nome a um bairro (Cambuci) próximo ao centro da cidade (PPSP, 2015). Atualmente o fruto dessa árvore está ameaçado de extinção e carece de maiores estudos (SILVA et al., 2012).

Essa espécie possui frutos de cor verde, com polpa carnosa e sabor doceacidulado, como o limão. Os frutos têm uma forma muito peculiar, que lembra o formato de um disco-voador ou pote de água dos índios. Acredita-se que o nome cambuci venha da palavra tupi-guarani para designar pote de água. O fruto do C. phaea é também consumido por vários pássaros e mamíferos, sendo estes os precursores de sua disseminação (VALLILO et al., 2005). 
Os frutos do cambuci não são encontrados facilmente no comércio fora da região da vila de Paranapiacaba, que se tornou uma das principais localidades a receber o Festival da Rota do Cambuci. O desenvolvimento do projeto para a comercialização de produtos feitos a partir de matéria prima do cambucié de essencial importância para as populações inseridas em áreas circunvizinhas de fragmentos florestais da região (PPSP, 2010), favorecendo e impulsionando maior conhecimento geral a respeito da espécie e sua importância ecológica, principalmente em áreas de Mata Atlântica.

Conforme trabalho divulgado por Cordeiro et al. (2013), a espécie não forma frutos por autopolinização manual e por aganospermia (transformação do óvulo em semente sem a fecundação), sendo classificada pela razão pólen/óvulo como espécie alógama obrigatória. Seu saboroso fruto é comestivel e ingerido principalmente na forma de suco. Uma de suas propriedades é seu elevado teor de ácido ascórbico

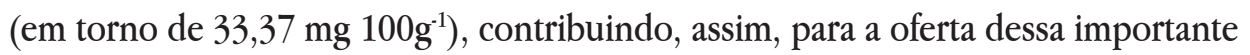
vitamina (CORDEIRO et al., 2013).

\subsection{COLETA DE DADOS}

O trabalho se deu com os moradores e comerciantes da vila de Paranapiacaba, no qual foram realizadas 50 entrevistas, aplicadas nos domicílios e comércios da região por três meses consecutivos no ano de 2014. Para cada morador, foram explicados os propósitos da entrevista e entregue um Termo de Consentimento Livre e Esclarecido (TCLE). Este foi assinado por cada entrevistado, permitindo, assim, o uso das informações e fotografias geradas nas entrevistas. O questionário e a proposta geral do presente trabalho foram aprovados pelo Comitê de Ética em Pesquisa com Humanos (CoEP), da Universidade Nove de Julho, sob o protocolo ${ }^{\circ}$ 907.233 .

O roteiro (Quadro 1) consistiu em perguntas abertas e utilizou-se o sistema bola de neve, em que cada entrevistado indicava outro informante para participar da pesquisa. Foram coletadas informações sobre a presença de árvores de cambuci (Campomanesia phaea) nos quintais das residências e comércios, hábitos de cultivos, envolvimento com o cambuci, nível de escolaridade, idade e tempo de residência na vila de Paranapiacaba. Os dados foram analisados qualitativamente. 
Quadro1. Roteiro de entrevistas utilizado com moradores e comerciantes na vila de Paranapiacaba

\begin{tabular}{|c|c|c|}
\hline Seção & Objetivo & Questões \\
\hline \multirow{3}{*}{$\begin{array}{l}\text { Caracterização do } \\
\text { grupo }\end{array}$} & \multirow{3}{*}{$\begin{array}{l}\text { Traçar um perfil social da } \\
\text { população que utiliza o } \\
\text { cambuci }\end{array}$} & $\begin{array}{l}\text { 1.Qual sua idade? } \\
\text { (1) De } 20 \text { a } 30 \\
\text { (2) De } 31 \text { a } 40 \\
\text { (3) De } 41 \text { a } 50 \\
\text { (4) De } 51 \text { a } 60 \\
\text { (5) Acima de } 60 \text { anos }\end{array}$ \\
\hline & & $\begin{array}{l}\text { 2. Qual a escolaridade? } \\
\text { (F)(M) (S) (P) }\end{array}$ \\
\hline & & $\begin{array}{l}\text { 3. Há quanto tempo mora/trabalha na vila } \\
\text { de Paranapiacaba? }\end{array}$ \\
\hline \multirow{9}{*}{$\begin{array}{l}\text { Cultivo e uso do } \\
\text { Cambuci }\end{array}$} & \multirow{9}{*}{$\begin{array}{l}\text { Descrever o } \\
\text { conhecimento da } \\
\text { população sobre o } \\
\text { cultivo e uso do cambuci }\end{array}$} & $\begin{array}{l}\text { 4. Você cultiva cambuci? Você conhece o } \\
\text { fruto do cambuci? }\end{array}$ \\
\hline & & $\begin{array}{l}\text { 5. Onde conseguiu a muda? Como você } \\
\text { adquire o fruto? }\end{array}$ \\
\hline & & $\begin{array}{l}\text { 6. Quais as formas de consumo do } \\
\text { cambuci? }\end{array}$ \\
\hline & & $\begin{array}{l}\text { 7. Com que frequência consome o } \\
\text { cambuci? (D) }(\mathrm{S})(\mathrm{M})(\mathrm{N})\end{array}$ \\
\hline & & $\begin{array}{l}\text { 8. Como obteve informações sobre o } \\
\text { cambuci? }\end{array}$ \\
\hline & & $\begin{array}{l}\text { 9. Quais os problemas enfrentados no } \\
\text { plantio? }\end{array}$ \\
\hline & & 10. Você molha as plantas? \\
\hline & & $\begin{array}{l}\text { 11. Você usa fertilizantes ou produtos } \\
\text { agrícolas? }\end{array}$ \\
\hline & & $\begin{array}{l}\text { 12. Qual o período de plantio? Meses } \\
\text { de floraçãa e frutificaçãa? E tempo para } \\
\text { produção? }\end{array}$ \\
\hline \multirow{4}{*}{$\begin{array}{l}\text { Conhecimentos e } \\
\text { contribuiçôes do } \\
\text { Cambuci }\end{array}$} & \multirow{4}{*}{$\begin{array}{l}\text { Investigar as } \\
\text { contribuições ecológicas } \\
\text { do Cambuci por meio } \\
\text { do conhecimento da } \\
\text { população }\end{array}$} & $\begin{array}{l}\text { 13.Para você, qual a importância do } \\
\text { cambuci? }\end{array}$ \\
\hline & & $\begin{array}{l}\text { 14. Qual importância do cambuci para } \\
\text { Paranapiacaba?? }\end{array}$ \\
\hline & & $\begin{array}{l}\text { 15. Quais animais se alimentam na árvore? } \\
\text { Eno solo? }\end{array}$ \\
\hline & & 16. Aves se alimentam da planta? \\
\hline
\end{tabular}


Para o levantamento de informações etnoecológicas sobre o cambuci, foram realizadas perguntas sobre período de floração e frutificação, visitantes florais, e possíveis dispersores de suas sementes. No levantamento etnobiológico, as perguntas foram sobre a importância que os moradores atribuem à espécie $\mathrm{e}$ sua relevância para a vila de Paranapiacaba, quais partes do fruto são utilizadas e suas formas de consumo, bem como modos de aquisição do fruto, frequência de consumo e exploração comercial.

\section{RESULTADOS E DISCUSSÃO}

De todos os 50 entrevistados, 26\% estudaram até a conclusão do ensino médio, 44\% cursaram o ensino fundamental II, mesmo que incompleto, 15\%, o ensino fundamental I, mesmo que incompleto também, 9\% eram analfabetos ou possuíam escolaridade até o ensino fundamental I e apenas $6 \%$ possuíam ensino superior completo. A idade média dos entrevistados foi de 51,4 anos de vida, e a maioria da população pesquisada encontrava-se na faixa da terceira idade com mais de 61 anos (30\%), seguida, respectivamente, por indivíduos com idades entre 51e 60 anos (24\%), 41 e 50 anos (22\%), 31 e 40 anos (12\%), encerrando-se na população mais jovem (20 a 30 anos), representada por 12\% da população pesquisada.

Tabela1. Perfil dos entrevistados da vila de Paranapiacaba, SP

(Continua)

\begin{tabular}{lcc}
\hline Variáveis & $\mathbf{N = 5 0}$ & $\%$ \\
\hline Faixa etária & & 22 \\
20 a 30 anos & 11 & 10 \\
31 a 40 anos & 5 & 20 \\
41 a 50 anos & 10 & 24 \\
51 a 60 anos & 12 & 24 \\
61 ou mais & 12 & \\
Nível de escolaridade & & \\
\hline
\end{tabular}


(Conclusão)

\begin{tabular}{lcc}
\hline Variáveis & $\mathbf{N = 5 0}$ & $\%$ \\
\hline Fundamental & 34 & 68 \\
Médio completo & 13 & 26 \\
Superior completo & 3 & 6 \\
Residente em Paranapiacaba & & \\
Até 10 anos & 6 & 12 \\
Entre 10 e 30 anos & 27 & 54 \\
Mais de 30 anos & 17 & 34 \\
Moradores & 40 & 80 \\
Comerciantes & 10 & 20 \\
\hline
\end{tabular}

A maioria dos residentes na vila de Paranapiacaba (54\%) moram no local entre dez e 30 anos, seguida dos que residem há mais de 30 anos (34\%) e os que residem há menos do que dez anos (12\%). Nota-se que, dentre os entrevistados, a maioria mora há mais de dez anos na região, indicando conhecimento sobre a vila e também sobre o cambuci. Além disso, $80 \%$ relatam morar na vila, mas não comercializar o cambuci.

Durante o período de entrevistas, $68 \%$ dos moradores entrevistados se declararam migrantes, o que salienta as dificuldades encontradas para permissão das gravações das entrevistas por parte dos residentes, pois o direito à moradia na vila se dá por meio de concessões cedidas pela prefeitura da cidade de Santo André, SP. Portanto, para a realização deste estudo, houve receio de participação nas entrevistas por parte de alguns moradores, principalmente por desconfiarem de ser uma pesquisa que pudesse prejudicá-los no direito à moradia.

Dentre os moradores entrevistados, 50\% cultivam o cambuci (Figura 1A) e $94 \%$ relataram conhecer os frutos da planta (Figura 1B), indicando que o grupo entrevistado possui conhecimentos para responder às perguntas deste trabalho. $\mathrm{O}$ uso estritamente comercial corresponde a $11 \%$ e os entrevistados que informaram possuir um contato unicamente pessoal com o cambuci são $57 \%$ do total. Apenas $13 \%$ das pessoas que aceitaram participar do estudo relataram não possuir nenhuma relação com o fruto. 


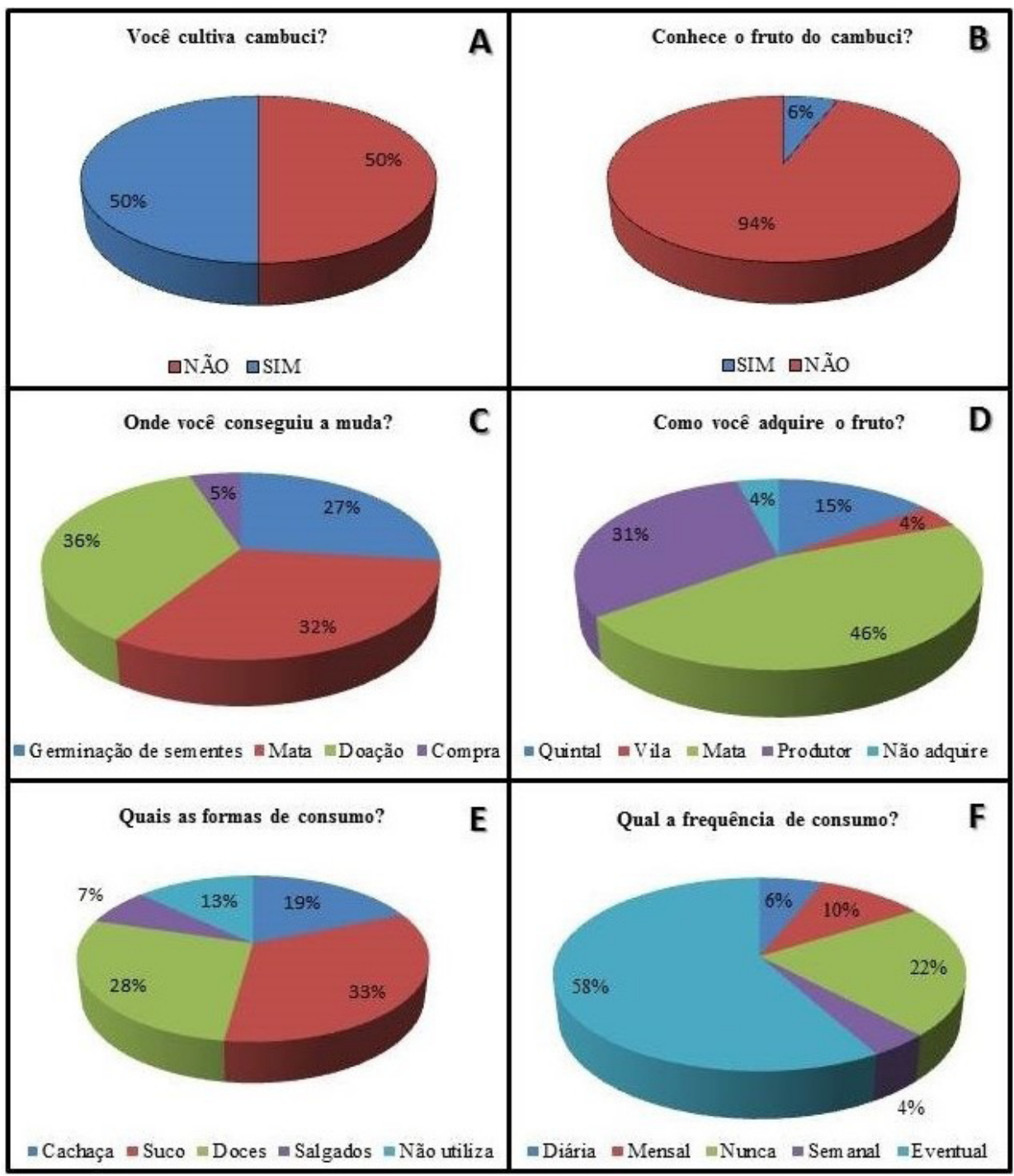

Figura 1. Informações sobre aquisição, cultivo e uso do cambuci pela população de Paranapiacaba, SP. Em A: cultivo do cambuci; em B: conhecimento sobre o fruto do cambuci; em C: aquisição da muda; em D: aquisição do fruto; em E: formas de consumo e em F: frequência de consumo.

Os entrevistados que cultivam o cambuci relatam que obtiveram a muda da planta de diferentes formas. As mais mencionadas são a doação de membros da comunidade (36\%), seguida por aqueles que conseguiram na mata (32\%), 
germinação de sementes (27\%) e por fim aqueles que compraram a muda (5\%) (Figura 1C). Pode-se observar que a doação de mudas supera o número de mudas retiradas da mata e da germinação de sementes para posterior produção da planta, sendo poucos que efetivamente compram as mudas do cambuci.

Em relação à fenologia de Campomanesia phaea, 21\% relatam que o período necessário para a produção de frutos é de aproximadamente cinco anos; $17 \%$ disseram ser de três anos; $10 \%$, dois anos; $8 \%$, dez anos; e $5 \%$ relataram que a espécie $C$. phaea torna-se produtiva em torno de 15 anos após seu plantio. Produtores próximos à localidade realizam visitas para venda de frutos do cambuci, sendo responsáveis por aproximadamente $31 \%$ de seu fornecimento. Além dos quintais que fornecem $15 \%$ dos frutos, há os próprios espécimes presentes na vila (4\%) e os moradores que não adquirem o fruto (4\%). Embora a forma de aquisição dos frutos ocorra de diversas formas, tanto para comerciantes quanto para residentes, a principal fonte de aquisição ainda é a retirada de frutos na mata (46\%).

Em relação aos indivíduos encontrados nos quintais, 56\% informaram terem sido eles próprios os responsáveis pelo plantio de seus cambucizeiros, 26\% dos entrevistados não souberam informar sua origem, e 18\% informaram ter sido resultado de árvores plantadas por vizinhos e outros parentes.

Essas e outras formas de impacto na mata são notadas pela própria população local que faz uso dos recursos naturais oferecidos, conforme relatado por alguns moradores:

"[...] há destruição das árvores da vila". (Moradora da comunidade de Paranapiacaba)

"Hoje o Cambuci é raro porque eles [as crianças e coletores ocasionais] quebram os galhos". (Comerciante ocasional de Paranapiacaba) "O Cambuci se tornou escasso" - "Ele nasce acima do rio..." "Eles [os mateiros locais] pegam verde e não serve nem pra cachaça" "Faltou empenho municipal pra preservar" (comerciante ocasional da comunidade de Paranapiacaba)

Deve-se considerar que a exploração direta ou indireta de produtos florestais pode acarretar em sérias consequências para a manutenção da biodiversidade (PERSHA et al., 2011), principalmente no que diz respeito a espécies dispersoras na Mata Atlântica, gerando risco para muitos grupos taxonômicos que habitam no local (MAGRACH et al., 2015). 
Em relação ao uso do fruto do cambuci na região, o suco é o mais utilizado (33\%), seguido pela produção de doces (28\%) e produção de cachaça e licores (19\%) (Figura 1E). Contudo, durante as entrevistas, foram apresentadas formas de uso mais recentemente incorporadas, como sua utilização na produção de salgados (7\%).

Para a maioria dos entrevistados (58\%), o consumo dos frutos do cambucizeiro ocorre de forma eventual e somente $22 \%$ informaram não realizar o consumo do fruto. Em relação à frequência de consumo, 10\% dos entrevistados relatam consumir mensalmente o fruto do cambucizeiro, seguidos de $6 \%$ que disseram consumi-lo diariamente, e $4 \%$ declaram um consumo semanal. Conforme mostra o relato por uma das residentes:

"[...] porque serve pra dor de garganta, a folha e a casca da fruta." (Moradora da comunidade de Paranapiacaba)

$\mathrm{O}$ uso de alimentos para fins medicinais por populações tradicionais tem sido amplamente relatado em estudos de etnobotânica (OLIVEIRA et al., 2009; FRANCO et al. 2013; PERNA; LAMANO-FERREIRA, 2015) nos quais a decocção de folhas, frutos e cascas é o principal meio de consumo. Botelho et al. (2014) mostraram que em cidades brasileiras das regiões Centro-Oeste e Nordeste grande parte dos entrevistados relatam utilizar plantas cultivadas nas residências para fins medicinais.

A troca de informações e consequentemente obtenção de conhecimento sobre o fruto do cambuci pela população da vila de Paranapiacaba ocorrem principalmente por meio do convívio entre os moradores (74\%), com os familiares (16\%) e apenas $10 \%$ dos entrevistados relatam não ter conhecimento sobre a planta (Figura 2A).

A maioria dos moradores (63\%) não relata dificuldade em relação ao cultivo do cambuci. Dentre as dificuldades relatadas, são apontados problemas climáticos (7\%), plantio (7\%), adubação (6\%), praga natural (4\%) e transporte (4\%) (Figura 2B). Dentre os moradores, $52 \%$ relatam não utilizar nenhum produto agrícola no cultivo da $C$. phea, seguidos de 38\% que mencionam praticar agricultura orgânica e 3\% que afirmam utilizar produtos agrícolas (Figura 2C). Cabe relatar que 7\% não souberam responder. Além disso, 8\% não souberam mencionar nenhuma dificuldade.

Essas informações mostram que, para a produção do cambucie provavelmente para outras culturas também, a população local não interfere de forma direta nas 
propriedades do solo local, uma vez que não fazem uso de fertilizantes. Atualmente há grande preocupação mundial pelo uso indiscriminado de adubação nitrogenada (AUSTIN et al., 2013; GROPPO et al., 2015) ainda mais em áreas próximas a unidades de conservação, onde os danos e alteração de processos ecossistêmicos poderiam acarretar sérios riscos para a biodiversidade local (CARMO et al., 2012).

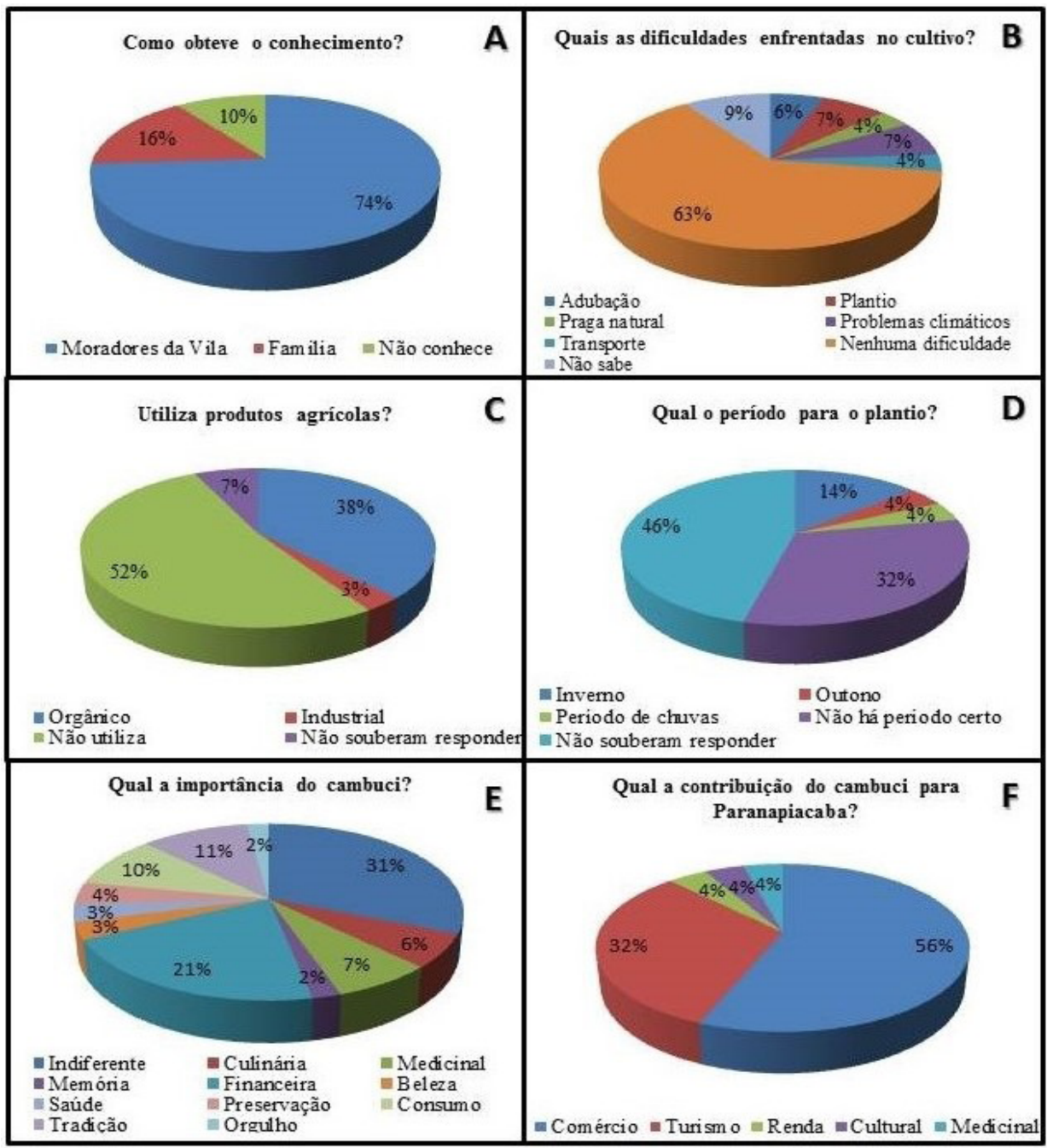

Figura 2. Cultivo e importância do cambuci para a população de Paranapiacaba, SP. Em A: obtenção de conhecimento; em B: dificuldades enfrentadas no cultivo; em C: utilização de produtos agrícolas; em D: período de plantio do cambuci; em E: importância do cambuci; e em F: importância do cambuci para a vila de Paranapiacaba. 
A não utilização de fertilizantes químicos e a forma natural de cultivar o cambucizeiro podem estar atreladas ao próprio saber da população local sobre a biologia e ecologia da espécie, mesmo que esse seja um conhecimento empírico. Isso se reforça com o discurso de um morador que, durante as entrevistas, relatou não possuir dificuldades na manutenção do cambucizeiro por ser uma espécie nativa da região: "porque é árvore do mato" (morador da comunidade de Paranapiacaba). Entretanto as insuficientes pesquisas com Campomanesia phaea referem sua grande vulnerabilidade para germinação, assim como a permanência de poucos indivíduos em análises florísticas, realizadas em áreas de Mata Atlântica (KAWASAKI; LANDRUM, 1997).

Em relação ao período de plantio (Figura 2D), 32\% dos entrevistados relatam não possuir um período específico, 14\% acreditam ser o inverno o melhor período de plantio, $4 \%$ mencionam os períodos com chuva e outros $4 \%$, no outono. O calendário reprodutivo de Campomanesia phaea, segundo as percepções dos entrevistados, encontra-se na Tabela 2.

Os meses de janeiro, fevereiro e março foram os mais citados para floração, com pico florístico no mês de março, sendo 12 citações, o que não corresponde às informações encontradas no trabalho de Vallilo et al. (2005). De acordo com os autores, a floração de Campomanesia phaea ocorre entre os meses de agosto e novembro, corroborando, assim, o trabalho divulgado por Andrade et al. (2011), que atesta o surgimento das flores hermafroditas durante esses meses. Isso demonstra que, mesmo convivendo e utilizando a espécie, a própria população pode ter dúvidas ou estar equivocada sobre a fenologia da planta.

Para o período de frutificação, os meses mais citados foram de janeiro a maio, com 34 citações para o mês de maio. Cabe mencionar que Vallilo et al. (2005), em seu trabalho com a Campomanesia phaea, ressaltam que o fruto apresenta limitações para consumo in natura, em razão do baixo teor de carboidratos e da acidez, entretanto os autores salientam o potencial do fruto para a industrialização.

Tabela 2. Calendário reprodutivo anual de cambuci (Campomanesia phaea) da vila de Paranapiacaba, Sudeste do Brasil

\begin{tabular}{lcccccccccccc}
\hline Meses & Jan & Fev & Mar & Abr & Mai & Jun & Jul & Ago & Set & Out & Nov & Dez \\
\hline $\begin{array}{l}\mathrm{n}^{\circ} \text {. citações } \\
\text { para flor }\end{array}$ & 7 & 6 & 12 & 4 & 1 & 1 & 1 & 0 & 4 & 4 & 2 & 4 \\
$\begin{array}{l}\mathrm{n}^{\mathrm{o}} \text {. citações } \\
\text { para fruto }\end{array}$ & 1 & 3 & 9 & 34 & 8 & 0 & 0 & 0 & 0 & 0 & 0 & 0 \\
\hline
\end{tabular}


A sabedoria acerca das plantas e o conhecimento de seus ciclos são comumente usados pelas populações na elaboração da melhor forma de organização para 0 uso de recursos, sendo que tais informações são normalmente passadas ao longo das gerações de pais para filhos para que o conhecimento secular a respeito do uso de vegetais não se perca ao longo do tempo (MOURA, 2007; PIRES et al., 2009).

Cabe destacar que o cambucitem diferente valor para os diferentes integrantes deste estudo. A importância da espécie vegetal para a população entrevistada pode ser observada na Figura 2E. Para 31\% dos entrevistados, os cambucizeiros são indiferentes, ou seja, não fazem parte direta de suas rotinas, porém, para 21\% deles, há um valor financeiro agregado ao fruto e, para 10\% dos entrevistados, o consumo dos frutos do cambuci é um motivo importante. Outras citações, porém, trazem uma vasta gama de motivos como tradição (7\%), valor medicinal (7\%), culinária (6\%), cultural (3\%), saúde e beleza (3\%), sua comercialização (3\%) e turismo (2\%). Também foram mencionados motivos ligados mais à afetividade das pessoas como o orgulho $(2 \%)$, memória $(2 \%)$ e preservação $(2 \%)$, além de formas mais práticas, como evitar a erosão do solo (2\%).

As diferentes percepções refletem as diferentes formas com que cada indivíduo ou população se relaciona com os recursos naturais (DORIGO; LAMANOFERREIRA, 2015). Muitas vezes a cultura local de determinada sociedade, sua percepção do meio e crenças estão intimamente ligadas às formas de manejo e utilização dos recursos naturais (MAGALHÃES, 2014), assim como demostrado em trabalho realizado por Moreira (2002), na comunidade de vila Cachoeira, BA.

Quando questionados sobre a contribuição do cambuci para a vila de Paranapiacaba (Figura 2F), 56\% dos entrevistados relatam as contribuições para o comércio, seguidas do turismo (32\%), como também geração de renda (4\%), aspectos culturais (4\%) e uso medicinal da planta (4\%). Isso demonstra que existe uma relação próxima entre as atividades urbanas da vila com a natureza. Torna-se fundamental que o cambuci continue sendo utilizado pela comunidade de Paranapiacaba, porém que esta seja instruída sobre algumas consequências que o uso indiscriminado pode gerar para o equilíbrio ecológico na região, mesmo se considerando que no discurso dos próprios entrevistados já exista certo grau de conhecimento conservacionista: 
"É importante os jovens saberem [dos problemas de não se ter o Cambuci] pra não mexer nos pés". (moradora da comunidade de Paranapiacaba)

"A preservação deve nascer a partir de um ponto [...] as cidades estão se envolvendo [com a preservação] através do Cambuci." (comerciante da comunidade de Paranapiacaba)

\subsection{CONHECIMENTOS ECOLÓGICOS DO CAMBUCI}

O polinizador do cambuci mais citado pelos entrevistados é a abelha africana do gênero Apis, com 29\% das citações, embora seu polinizador mais efetivo sejam abelhas da tribo Eucerini (SOUZA, 2010). Para 7\% dos entrevistados, a formiga é o visitante floral mais comum, seguida de marimbondos (2\%); abelha italianinha (2\%); abelha jatinho (2\%); borboleta (2\%); abelha arapuá (2\%); mosquitinha (2\%). Alguns entrevistados declaram a lagarta (2\%) como principal visitante floral do cambucizeiro.

Em relação à dispersão das sementes da $C$. phea, $9 \%$ informaram avistar pacas se alimentando do fruto, sendo esses mamíferos os grandes responsáveis pela disseminação desses frutos pelo solo da floresta (LANDRUM, 1986; FRANCO, 2006; 2007). Além disso, 5\% citaram avistar cotias, bem como outros 5\% informaram as maritacas. Também são citados porco-do-mato (3\%), caramujos (2\%), serelepe (2\%), quati (2\%) e besouro (2\%). Contudo há moradores que acreditam não existir nenhum animal que se alimente do fruto (2\%) e outros que nunca observaram animais se alimentarem dos frutos dos cambucizeiros (59\%).

Os nomes populares de aves que se alimentam do fruto de cambuci também podem ser visualizados na Tabela 3. A maritaca é a ave mais mencionada (12\%), seguida de tucano (8\%), periquito (5\%), jacu (5\%), beija-flor (5\%). Foi também verificada a presença de tico-tico (4\%), sabiá (3\%), sanhaço (2\%), currivira (2\%), papagaio (2\%), jandaia (2\%), macuco (2\%), arara (2\%), baitaca (2\%), caroço $(2 \%)$, pássaro-preto (2\%), araçari (2\%) e tivira (2\%). Apesar do grande número de aves citadas, para Gressler et al. (2006), a diversidade de dispersores para cabucizeiros é pequena, sugerindo que as aves tenham pouca influência na sua dispersão. 
Tabela 3. Grupos de animais (mamíferos, aves e insetos) mencionados durante as entrevistas, por visitarem a Campomanesia phaea

(Continua) total \% entre animais \% no grupo Local de visita

Característica ecológica

\begin{tabular}{|c|c|c|c|c|c|}
\hline Mamíferos & & & & & \\
\hline cotia & 3 & 3,23 & 15,79 & solo & \# \\
\hline macaco & 4 & 4,30 & 21,05 & árvore & dispersão \\
\hline mico & 1 & 1,08 & 5,26 & árvore & dispersão \\
\hline paca & 5 & 5,38 & 26,32 & solo & \# \\
\hline $\begin{array}{l}\text { porco do } \\
\text { mato }\end{array}$ & 2 & 2,15 & 10,53 & solo & \# \\
\hline preguiça & 1 & 1,08 & 5,26 & árvore & dispersão \\
\hline quati & 1 & 1,08 & 5,26 & solo & \# \\
\hline sagui & 2 & 2,15 & 10,53 & árvore & dispersão \\
\hline Total & 19 & & & & \\
\hline \multicolumn{6}{|l|}{ Aves } \\
\hline araçari & 1 & 1,08 & 2,08 & árvore & dispersão \\
\hline arara & 1 & 1,08 & 2,08 & árvore & dispersão \\
\hline aves & 8 & 8,60 & 16,67 & solo & dispersão \\
\hline baitaca & 1 & 1,08 & 2,08 & árvore & dispersão \\
\hline beija-flor & 4 & 4,30 & 8,33 & árvore & dispersão \\
\hline curruvira & 1 & 1,08 & 2,08 & árvore & dispersão \\
\hline jacu & 4 & 4,30 & 8,33 & árvore & dispersão \\
\hline jandaia & 1 & 1,08 & 2,08 & árvore & dispersão \\
\hline maritaca & 9 & 9,68 & 18,75 & árvore & dispersão \\
\hline papagaio & 2 & 2,15 & 4,17 & árvore & dispersão \\
\hline passaro preto & 1 & 1,08 & 2,08 & árvore & dispersão \\
\hline periquito & 3 & 3,23 & 6,25 & árvore & dispersão \\
\hline sabiá & 2 & 2,15 & 4,17 & árvore & dispersão \\
\hline sanhaço & 1 & 1,08 & 2,08 & árvore & dispersão \\
\hline tico-tico & 3 & 3,23 & 6,25 & árvore & dispersão \\
\hline tiriba & 1 & 1,08 & 2,08 & árvore & dispersão \\
\hline tucano & 5 & 5,38 & 10,42 & árvore & dispersão \\
\hline
\end{tabular}


(Conclusão)

total $\%$ entre animais $\%$ no grupo Local de visita

Característica

ecológica

\begin{tabular}{cccccc}
\hline Insetos & & & & & \\
\hline abelha & 18 & 19,35 & 69,23 & flor & polinização \\
besouro & 1 & 1,08 & 3,85 & solo & dispersão \\
borboleta & 2 & 2,15 & 7,69 & flor & Polinização \\
formiga & 4 & 4,30 & 15,38 & flor & Polinização \\
mosquitinho & 1 & 1,08 & 3,85 & flor & Polinização \\
\hline Total & 26 & & & \\
\hline
\end{tabular}

\# sem citação pelos entrevistados

De acordo com os entrevistados, a maioria dos animais que se alimentam de frutos de cambuci nas árvores são as aves (21\%), os macacos (14\%) e a preguiça (2\%). No entanto $20 \%$ dos entrevistados não souberam responder a essa pergunta, e apenas $2 \%$ informaram que nenhum animal se alimenta de Campomanesia phaea na própria árvore. A maritaca foi a ave mais citada pelos entrevistados (12\%), seguida de tucano (8\%) e jacu e pássaro-preto, com 5\%, respectivamente. A maneira como os animais se alimentam e quais partes do fruto são consumidas por eles não foram verificadas neste estudo. Entretanto um levantamento aprofundado das espécies de aves que se alimentam de Campomanesia phaea seria fundamental para o entendimento da efetiva participação das aves na disseminação de suas sementes.

Em complementariedade a esses dados, trabalhos técnicos para melhor cultivo de espécies vegetais nativas e/ou endêmicas são de grande valia para aumentar ou inserir seu consumo no mercado, conforme caso ocorrido com o cambuci, em trabalho citado por Maluf e Pisciottano (2005), o qual, ao estudar as formas de secagem e armazenamento de suas sementes, relata que, para a sua produção, deve-se considerar a menor perda possível, pois cada fruto de cambuci produz em média 4,65 sementes. Dessa forma, o acesso às sementes por possíveis produtores de cambuci manteria sua produção para usos diversos, tanto para produtos que possuem como matéria prima o fruto do cambuci, como para sua utilização na farmacologia, uma vez que há tão poucos estudos sobre as propriedades medicinais desse fruto. 
Muito embora Campomanesia phaea seja uma espécie pioneira na região (SOUZA et al. s/d), a degradação de seu habitat original que circunda a vila sobrevém ao aumento da procura de seu fruto pelos moradores locais, refletindo, assim, os dizeres de um morador:

"[... ] Foi doado mudas, mas não teve o cuidado de saber o que aconteceu com o Cambuci" [mudas doadas pela prefeitura].

"Tem pé que só eles [os mateiros] sabem onde tem [...]"

"Deveria ter uma associação, uma cooperativa pra vender Cambuci".

Para 56\% da população local, os moradores contribuem para a preservação de Campomanesia phaea, contra os $44 \%$ que acreditam haver mais degradação do que preservação. Isso demonstra que a maioria da população local entrevistada da Vila de Paranapiacaba se encontra em sinergismo com a conservação e manutenção da espécie na região, embora seus usos e interações com a planta se diversifiquem conforme a sua história de vida.

\section{CONCLUSÃO}

Os moradores mencionaram diversas formas de uso dos cambucizeiros e sua importância econômica não apenas para a vila de Paranapiacaba, conhecida turisticamente, mas também para a comunidade como um todo.

Nota-se que os próprios moradores obtêm suas respectivas mudas e frutos do cambuci, muitas vezes os extraindo da mata ou pegando com outros moradores locais. Apesar de um provável impacto, por utilizarem uma área de conservação para a exploração desse recurso vegetal, os moradores não impactam o solo na produção da espécie. Dentre as contribuições do cambuci para a vila de Paranapiacaba, destacase o uso como alimento sendo consumido e comercializado em diversas formas como geleias, licores, cachaça, mousse, sorvete, bolo, além do tradicional suco.

A população local mostrou bastante conhecimento sobre outros organismos que interagem com a Campomanesia phaea, destacando papel fundamental a polinizadores e dispersores que matem o patrimônio genético nessa região da Mata Atlântica. Ainda cabe ressaltar que a relação da população com o cambuci contribui 
para sua conservação, uma vez que cultiva e utiliza árvores frutíferas ameaçadas de extinção.

\section{AGRADECIMENTOS}

Ao curador do Herbário Municipal de São Paulo, Ricardo J.F. Garcia, e a Eduardo H.P. Barretto, pela identificação e depósito da espécie Campomanesia phaea (O. Berg) Landrum sob o número de tombo PMSP 16163.

\section{REFERÊNCIAS}

ANDRADE, B.A.G.F.; FONSECA, P.Y.G.; LEMOS, F. Cambuci - o fruto, o bairro, a rota: história, cultura, sustentabilidade e gastronomia. São Paulo: Ouriversaria da Palavra, 2011. 176 p.

AUSTIN, A.T.; BUSTAMANTE, M.M.C.; NARDOTO, G.B.; MITRE, S.K.; PEREZ, T.; OMETTO, J.P.H.B.; ASCARRUNZ, N.L.; FORTI, M.C.; LONGO, K.; GAVITO, M.E.; ENRICH-PRAST, A.; MARTINELLI, L.A. Latin America's Nitrogen Challenge. Science, Nova Iorque, v. 340, p. 149-149, 2013.

BALDAUF, C.; KUBO, R.R.; SILVA, F.; IRGANG, B.E. "Ferveu, queimou o ser da erva": conhecimento de especialistas locais sobre plantas medicinais na região Sul do Brasil. Rev. Bras. Plantas Med., Botucatu, v. 11, n. 3, p. 282-291, 2009.

BOTELHO, J.M. LAMANO-FERREIRA, A.P.N.; FERREIRA, M.L. Prática de cultivo e uso de plantas domésticas em diferentes cidades brasileiras. Ciência Rural, Santa Maria, v. 44, n. 10, p. 1810-1815, 2014.

CORDEIRO, G.D.; PINHEIRO, M.; SANTOS, I.A. Polinizadores e sucesso reprodutivo de Campomanesia phaea (Myrtaceae). In: CONGRESSO NACIONAL DE BOTÂNICA, 64., Belo Horizonte. Anais... 2013. 
CARMO, J.B.; DE SOUSA NETO, E. R.; J.; OMETTO, J. P. H. B.; MARTINELLI, L. A.; R. Conversion of the coastal Atlantic forest to pasture: Consequences for the nitrogen cycle and soil greenhouse gas emissions. Agriculture, Ecosystems \& Environment, v. 148, p. 37-43, 2012.

CINCOTTA, R.P.; WISNEWSKI, J.; ENGELMAN, R. Human population in the biodiversity hotspots. Nature, v. 404, n. 6781, p. 990-992, 2000.

DORIGO, T.A.; LAMANO-FERREIRA, A.P.N. Contribuições da Percepção Ambiental de Frequentadores sobre Praças e Parques no Brasil (2009-2013): Revisão Bibliográfica. Revista de Gestao Ambiental e Sustentabilidade, v. 4, p. 31-45, 2015. Disponível em: <http://www.revistageas.org.br/ojs/index.php/geas/article/view/138>. Acesso em: 20 jan. 2016.

FARIA, A.A. Etnoconservação como política de meio ambiente no Brasil: desafios políticos de resistência e integração ao mundo globalizado. Agroecol. Desenv. Rur. Sustent., Porto Alegre, v. 3, n. 3, 2002. Disponível em: <http://www. projetovidanocampo.com.br/agroecologia/etnoconservacao_como_politica_de meio_ambiente.pdf >. Acesso em: 20 jan. 2016.

FRANCO, F.; Nascimento-Lamano, A.P.; FERREIRA, M.L. Etnobotânica: aspectos históricos e aplicativos desta ciência. Cadernos de Cultura e Ciência (URCA), v. 10, p. 17-22, 2013.

FRANCO, G.A.D.C. Avaliação integrada de remanescentes florestais de EmbuSP. São Paulo: Secretaria de Estado de Meio Ambiente, Instituto Florestal, 2006. 67p.

FRANCO, G.A.D.C. Importância dos remanescentes florestais de Embu (SP, Brasil) para a conservação da flora regional. Biota Neotrop., São Paulo, v. 7, n. 3, p. 147$161,2007$.

GRESSLER, E.; PIZO, M.A.; MORELLATO, L.P.C. Polinização e dispersão de sementes em Myrtaceae do Brasil. Rev. Bras. Botânica, São Paulo, v. 29, n. 4, p. 509-530, 2006. 
GROPPO, J.D.; LINS, S.R.M. ; CAMARGO, P.B. ; ASSAD, E.D. ; PINTO, H. S.; MARTINS, S.C.; SALGADO, P.R.; EVANGELISTA, B.; VASCONCELLOS, E.; SANO, E.E. ; PAVÃO, E. ; LUNA, R. ; MARTINELLI, L.A. Changes in soil carbon, nitrogen and phosphorus due to land-use changes in Brazil. Biogeosciences Discussion (Online), v. 12, p. 25332571, 2015.

KAWASAKI, M.L.; LANDRUM, L.R. Notes on economic plants. Econ. Bot., New York, v. 51, n. 4, p. 403-407, 1997.

LAMANO-FERREIRA, A.P.N.; FERREIRA, M.L.; FRANCOS, M.S. ; MOLINA, S.M.G. Espaços residenciais urbanos e suas implicações na conservação da biodiversidade. In: BENINI, S.M.; ROSIN, J.A.R.G. (Org.). Estudos Urbanos: uma abordagem interdisciplinar da cidade contemporânea. 2. ed. Tupã: ANAP, 2016, p. 349-362.

LANDRUM, L.R. Campomanesia, Pimenta, Blepharocalyx, Legrandia, Acca, Myrrbinium, and Luma (Myrtaceae). Flora Neotropica monograph., New York, v. 45, n. 1, p. 178, 1986.

LORENZI, H. Árvores brasileiras: manual de identificação e cultivo de plantas arbóreas nativas do Brasil. Nova Odessa: Plantarum, 1992. 352 p.

MAGALHÃES, H.F.; NETO, E.M.C.; SCHIAVETTI, A. Cosmovisão e etnoconservação nos manguezais do município de Conde, litoral norte do estado da Bahia, Brasil. Etnobiologia, Bahia, v. 12, n. 1, p. 23-29, 2014.

MAGRACH, A.; RODRIGUEZ-PERES, J.; PIAZZON, L.S. Divergent effects of forest edges on host distribution and seed disperser activity influence mistletoe distribution and recruitment. Journal of Ecology, v. 103, n. 6, p. 1475-1486, 2015.

MALUF, A.M.; PISCIOTTANO, W.A. Secagem e armazenamento das sementes de cambuci. Pesq. Agropec., Brasília, v. 401, n. 7, p. 707-714, 2005.

MING, L. C. A etnobotânica na recuperação do conhecimento popular. In: ENCONTRO INTERNACIONAL DE AGROECOLOGIA E DESENVOLVIMENTO RURAL SUSTENTÁVEL, 1., Botucatu, 2001. Anais... Disponível em: <http:// 
fazendadocerrado.com.br/Lin_Chau_Ming.pdf>.Acesso em: 20 jan. 2016.

MONTELES, R.; PINHEIRO, C.U.B. Plantas medicinais em um quilombo maranhense: uma perspectiva etnobotânica. Rev. Biol. Ciência da Terra, Maranhão, v. 7, n. 2, p. $12,2007$.

MOREIRA, R.C.T.; COSTA, L.C.B.; COSTA, R.C.S.; ROCHA, E.A. Abordagem etnobotânica acerca do uso de plantas medicinais na Vila Cachoeira, Ilhéus, Bahia, Brasil. Acta Farm. Bom., Argentina, v. 21, n. 3, p. 205-211, 2002.

MOURA, F.B.P.; MARQUES, J.G.W. Conhecimento de pescadores tradicionais sobre a dinâmica espaço-temporal de recursos naturais na Chapada Diamantina, Bahia. Biota Neotrop., Campinas, v. 7, n. 3, 2007.

OLIVEIRA, F.C.; ALBUQUERQUE, U.P.; FONSECA-KRUEL, V.S.; HANAZAKI, N. Avanços nas pesquisas etnobotânicas no Brasil. Acta bot. bras. v. 23, n. 2, p. 590-605, 2009. Disponível em: <http://www.scielo.br/pdf/abb/v23n2/v23n2a31>. Acesso em: 20 jan. 2016.

PEREIRA, B.E.; DIEGUES, A.C. Conhecimento de populações tradicionais como possibilidade de conservação da natureza: uma reflexão sobre a perspectiva da etnoconservação. Desenvolvimento e Meio Ambiente, Curitiba, n. 22, p. 37 50, 2010. Disponível em: <http://ojs.c3sl.ufpr.br/ojs/index.php/made/article/ view/16054/13504>. Acesso em: 20 jan. 2016.

PERSHA, L.; AGRAWAL, A.; CHHATRE, A. Social and Ecological Synergy: Local Rulemaking, Forest Livelihoods, and Biodiversity Conservation. Science, Nova Iorque, v. 331, n. 6024, p. 1606-1608, 2011.

PIRES, V.M.; ABREU, P. P.; SOARES, C.S.; SOUZA, B.; MARIANO, D.; SILVA, C.D.; ROCHA, E. A.Etnobotânica de terreiros de candomblé nos municípios de Ilhéus e Itabuna, Bahia, Brasil.Rev. Bras. Biocien., Porto Alegre, v. 7, n. 1, p. 3-8, 2009. Disponível em: <http://www.ufrgs.br/seerbio/ojs/index.php/rbb/article/ view/1108>. Acesso em: 20 jan. 2016. 
PPSP. Portal da Prefeitura de São Paulo. Disponível em: < http://www.prefeitura. sp.gov.br/cidade/secretarias/subprefeituras/se/noticias/?p=44400>. Acesso em 03 fev. 2015.

PPSP. Prefeitura de São Paulo. In: SEMINÁRIO COMPARTILHANDO CONHECIMENTO SOBRE O CAMBUCI - CampomanesiaPhaea., 1., São Paulo. Anais.. Incubadora de Projetos Sociais da Prefeitura de São Paulo, 2010. Disponível em: <www.prefeitura. sp.gov.br/incubadora > . Acesso em: 20 de maio 2010.

PSA. Prefeitura Municipal de Santo André. Secretaria de Gestão de Recursos Naturais de Paranapiacaba e Parque Andreense. Vila de Paranapiacaba. Disponível em: $\quad$ <http://www2.santoandre.sp.gov.br/index.php/acoes-e-programas-sgrpp/34secretarias/paranapiacaba-e-parque-andreense/269-vila-de-paranapiacaba $>$. Acesso em: 6 maio 2014.

SARMENTO, A.S.M.; BARBOSA C.; CASTELLANI, T.T.; HANAZAKI, N. Interferência Humana no Estabelecimento e Distribuição de Furcraeafoetida (L.) Haw (Agavaceae) na Praia Mole, Ilha de Santa Catarina, Brasil: Uma Interface entre Etnobotânica e Espécies Exóticas Invasoras. Biodiversidade Brasileira, v. 3, n. 2, p. 175-191, 2013. Disponível em: <http://www.icmbio.gov.br/revistaeletronica/index.php/BioBR/ article/view/325/372>. Acesso em: 20 jan. 2016.

SILVA, I.G.; CORREIA, A.F.K; BIGARAN, J.T.; BAPTISTA, C.P.; CARMO, L.F.; SPOTO, M.H. Estudo de caracterização do fruto cambuci [Campomanesia phaea (o. Berg.) Landrum] e sua aplicação no processamento de geleia. B. Ceppa, Curitiba, v. 30, n. 1, p. 83-90, 2012.

SIVIERO, A.; DELUNARDO, T.A.; HAVERROTH, M.; OLIVEIRA, L.C.; MENDONÇA, A.M.S. Cultivo de Espécies Alimentares em Quintais Urbanos de Rio Branco, Acre, Brasil. Acta Bot. Bras., 25(3): 549-556 2011. Disponível em: < http://www.scielo. br/scielo.php?pid $=$ S0102-33062011000300006\&script $=$ sci_arttext $>$. Acesso em: 20 jan. 2016.

SOUZA, L.S. Enriquecimento com Campomanesia phaea (berg.) Landr. E 
Euterpe edulis Martius em fragmentos de floresta ombrófila densa em estádio secundário. Botucatu: UNESP, 2011. 62p. Disponível em: <http://repositorio. unesp.br/handle/11449/99749> . Acesso em: 20 jan. 2016.

SOUZA, A.M.; CARBONI, M.; VIEIRA, A.S. Riqueza em espécies arbóreas utilizadas no Projeto Mata Ciliar na Microbacia do Santo Antonio no município de JAÚ-SP. Instituto Pró-Terra, [s.l.; s.d.]. Disponível em: $<$ http://www.institutoproterra.org. br/attach/upload/artigoriquezadeespeciesmataciliar.pdf> . Acesso em: 20 jan. 2016.

TOLEDO, V.M. Povos/Comunidades tradicionais e a biodiversidade - Instituto de Ecologia, UNAM, México. Trad.: Antonio Diegues. In: LEVIN, S. (Org.). Encyclopedia of Biodiversity. New York: Academic Press, 2001.

VALLILO, M.I.; GARBELOTTI, M.L.; OLIVEIRA, E.; LAMARDO, L.C.A. Características físicas e químicas dos frutos do cambucizeiro (Campomanesiaphaea). Rev. Bras. Frutic., Jaboticabal, v. 7, n. 2, p. 241-244, 2005. Disponível em: < http://www.scielo. $\mathrm{br} / \mathrm{pdf} / \mathrm{rbf} / \mathrm{v} 27 \mathrm{n} 2 / \mathrm{a} 14 \mathrm{v} 27 \mathrm{n} 2 . \mathrm{pdf}>$. Acesso em: $20 \mathrm{jan} .2016$.

VIGANÓ, J.; VIGANÓ, A.J.; SILVA, C.T.A.C. Utilização de plantas medicinais pela população da região urbana de Três Barras do Paraná.Acta Sci. Health Sci, Maringá, v. 29, n. 1, p. 51-58, 2007. Disponível em: < http://eduem.uem.br/ojs/index.php/ ActaSciHealthSci/article/viewArticle/106> . Acesso em: 20 jan. 2016.

Recebido em: 2016-02-03 Aceito em: 2016-10-18 